\title{
Neurosteroids and Focal Epileptic Disorders
}

\author{
Maxime Lévesque ${ }^{1, *}$, Giuseppe Biagini ${ }^{2}$ [D and Massimo Avoli ${ }^{1,3}$ \\ 1 Montreal Neurological Institute-Hospital \& Department of Neurology and Neurosurgery, \\ 3801 University Street, Montreal, QC H3A 2B4, Canada; massimo.avoli@mcgill.ca \\ 2 Department of Biomedical, Metabolic and Neural Sciences, University of Modena and Reggio Emilia, \\ Via Università 4, 41121 Modena, Italy; giuseppe.biagini@unimore.it \\ 3 Department of Physiology, McGill University, Montreal, QC H3A 2B4, Canada \\ * Correspondence: maxime.levesque2@mcgill.ca; Tel.: +1-514-398-8909
}

Received: 28 September 2020; Accepted: 8 December 2020; Published: 10 December 2020

check for updates

\begin{abstract}
Neurosteroids are a family of compounds that are synthesized in principal excitatory neurons and glial cells, and derive from the transformation of cholesterol into pregnenolone. The most studied neurosteroids-allopregnanolone and allotetrahydrodeoxycorticosterone (THDOC) - are known to modulate $\mathrm{GABA}_{\mathrm{A}}$ receptor-mediated transmission, thus playing a role in controlling neuronal network excitability. Given the role of $\mathrm{GABA}_{\mathrm{A}}$ signaling in epileptic disorders, neurosteroids have profound effects on seizure generation and play a role in the development of chronic epileptic conditions (i.e., epileptogenesis). We review here studies showing the effects induced by neurosteroids on epileptiform synchronization in in vitro brain slices, on epileptic activity in in vivo models, i.e., in animals that were made epileptic with chemoconvulsant treatment, and in epileptic patients. These studies reveal that neurosteroids can modulate ictogenesis and the occurrence of pathological network activity such as interictal spikes and high-frequency oscillations $(80-500 \mathrm{~Hz})$. Moreover, they can delay the onset of spontaneous seizures in animal models of mesial temporal lobe epilepsy. Overall, this evidence suggests that neurosteroids represent a new target for the treatment of focal epileptic disorders.
\end{abstract}

Keywords: neurosteroids; epilepsy; allopregnanolone; allotetrahydrodeoxycorticosterone; GABA; epileptogenesis; ictogenesis

\section{Introduction}

Neurosteroids are a class of compounds that modulate neuronal excitability at the level of ion channels and membrane receptors [1-3]. They fall into three main classes, i.e., sulfated, pregnane, and androstane neurosteroids [4]. The first class exerts excitatory effects, while the latter two play inhibitory roles [4,5]. For instance, sulfated neurosteroids can increase neuronal excitability by interacting with the picrotoxin (PTX) site of the $\mathrm{GABA}_{\mathrm{A}}$ receptor [6,7] or by acting as a positive allosteric modulator of the NMDA receptor [8]. In contrast, pregnane neurosteroids, such as allopregnanolone, pregnanolone and allotetrahydrodeoxycorticosterone (THDOC), positively modulate $\mathrm{GABA}_{\mathrm{A}}$ signaling [9]. Given the role of GABA-mediated activity in epileptic disorders, pregnane neurosteroids can act as broad spectrum anti-convulsants [10-17] that modulate the efficacy of $\mathrm{GABA}_{\mathrm{A}}$ receptor function to enhance inhibition in the brain [18-22]. Allopregnanolone and THDOC are synthesized in the brain from the transformation of cholesterol into pregnenolone by the cytochrome P450 cholesterol side chain cleavage (P450scc), independently of peripheral organs such as the ovaries and adrenal glands [2]. Accordingly, P450scc is expressed in various brain regions, such as the amygdala, hippocampus, thalamus, hypothalamus, cortex, cerebellum and olfactory bulb [2,3,23,24]. P450scc is mostly located in glial cells and principal neurons, whereas its expression is limited in interneurons $[2,4,11,23]$. 
In 1986, Majewska et al. discovered that allopregnanolone is a potent allosteric modulator of $\mathrm{GABA}_{\mathrm{A}}$ receptors [4,25]. In 1997, Zhu and Vicini [26] found that THDOC increases the open probability of $\mathrm{GABA}_{\mathrm{A}}$ receptor channels by facilitating late channel openings, while, a few years later, it was shown that it can potentiate both $\mathrm{GABA}_{\mathrm{A}}$ receptor phasic and tonic currents [10,27]. It is worth noting that the presence of the $\delta$ subunit in the $\mathrm{GABA}_{\mathrm{A}}$ receptor confers greater transduction of the neurosteroids action $[27,28]$. GABA $\mathrm{A}_{\mathrm{A}}$ receptors containing the $\delta$ subunit are mainly found extrasynaptically, are more resistant than synaptic receptors to desensitization and have a low affinity to GABA, even at saturating concentrations $[27,29]$. Allopregnanolone and THDOC can enhance the tonic current generated by activating these $\delta \mathrm{GABA}_{\mathrm{A}}$ receptors $[30,31]$.

We will review here recent evidence showing that neurosteroids can modulate epileptiform synchronization in vitro, as well as ictal and interictal activities in animal models of mesial temporal lobe epilepsy (MTLE) and in epileptic patients. In addition, neurosteroids appear to be able to alter the processes leading to epileptogenesis. Overall, these studies lead us to conclude that neurosteroids may represent a new therapeutic target for the treatment of human focal epileptic disorders.

\section{Effects on 4-Aminopyridine-Induced Epileptiform Synchronization In Vitro}

An early in vitro study performed in rat hippocampal slices reported that the neurosteroid allopregnanolone ( $5 \alpha$-pregnan-3 $\alpha$-ol-20-one), its $5 \beta$-epimer pregnanolone and pregnenolone sulfate can modulate the spontaneous interictal-like epileptiform discharges induced in the CA3 region by the $\mathrm{GABA}_{\mathrm{A}}$ receptor antagonist picrotoxin or the voltage-gated $\mathrm{K}^{+}$channel blocker 4-aminopyridine (4AP) [32]. 4AP is known to indirectly enhance $\mathrm{Ca}^{2+}$ entry into presynaptic nerve terminals, thus increasing neurotransmitter release at both excitatory and inhibitory synapses (see for a review Avoli et al. [33]; Avoli and de Curtis [34]). In this study, Salazar et al. [32] found a concentration-dependent ability of allopregnanolone to reduce both PTX- and 4AP-induced interictal spiking while $5 \beta$-epimer pregnanolone failed to alter PTX-induced but was partially effective on the 4AP-induced activity. In addition, pregnenolone sulfate increased the frequency of both PTX-induced bursting, while in the $4 \mathrm{AP}$ model it increased the frequency of a specific type of interictal event [32].

It is well established that 4AP induces two types of spontaneous interictal discharges-which have been identified as fast and slow events-in the isolated hippocampal slice preparation [35]. The fast events (arrows in Figure 1A, CA3 trace) mirror the synchronous discharge of CA3 pyramidal cells that are interconnected through glutamatergic excitatory synapses, while the slow events (asterisks in Figure 1A, CA3 trace) mainly reflect the synchronous firing of inhibitory interneurons leading to GABA release and subsequent activation of GABA receptor subtypes. In keeping with this view, 4AP-induced slow interictal events disappear during $\mathrm{GABA}_{\mathrm{A}}$ receptor antagonism, while they continue to occur and propagate in the absence of glutamate-mediated synaptic transmission; it has been proposed that these latter, glutamatergic-independent phenomena depend on gap-junctions and the excitatory effects caused by the concomitant occurrence of transient elevations in $\left[\mathrm{K}^{+}\right]$(see for review Avoli et al. [33]; Avoli and de Curtis [34]).

More complex patterns of spontaneous epileptiform discharge are, however, recorded during $4 \mathrm{AP}$ application in extended brain slices that include limbic or olfactory cortical structures $[33,34]$. As shown in Figure 1Aa (grey bar), in addition to the two types of interictal discharge (panel b and c), prolonged periods of epileptiform synchronization-which resemble ictal events-can occur in combined hippocampus-entorhinal cortex slices [36]. These ictal discharges appear to initiate in the entorhinal or perirhinal cortices as well as in the amygdala depending on the type of cut used to obtain extended brain slices that include specific areas. Moreover, both slow interictal and ictal discharges have been recorded from the piriform (Figure 1B, (grey bars) [37], insular [38] or cingulate cortices [39] in in vitro rodent brain slices. Finally, as reported in EEG recordings obtained in vivo from epileptic patients [40-42] or rodents [40,43], the epileptiform activity generated in vitro by brain slices is characterized by the occurrence of high frequency oscillations (HFOs, $80-500 \mathrm{~Hz}$ ). 

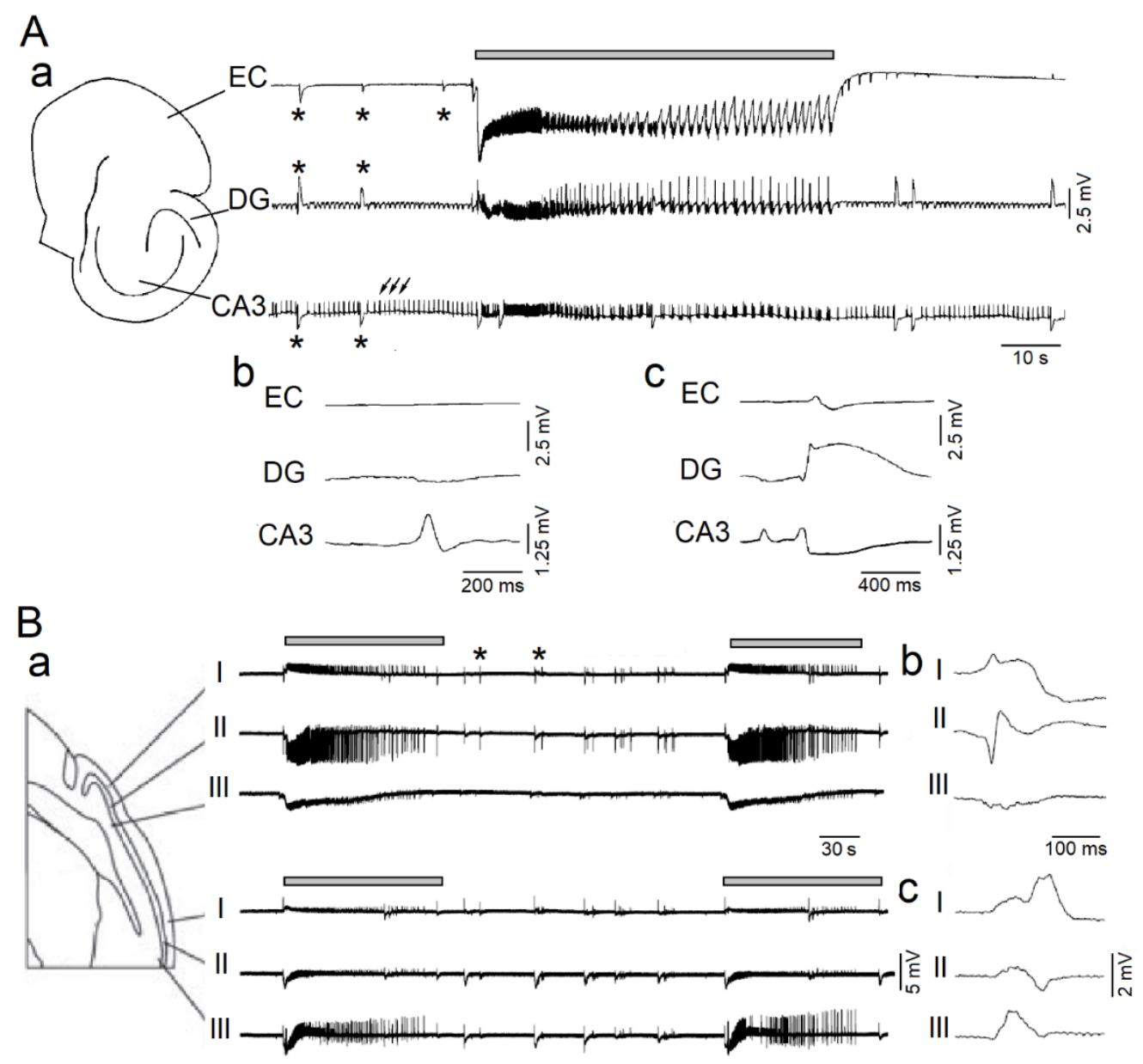

Figure 1. Epileptiform patterns induced by 4-aminopyridine (4AP) in rodent brain slices including the hippocampus-entorhinal cortex or the piriform cortex. (A): In panel (a), simultaneous field potential recordings obtained from the entorhinal cortex (EC), dentate gyrus (DG) and CA3 subfield of the hippocampus show the occurrence of three different types of epileptiform activity; the first (grey line)—which is recorded synchronously in all areas—consists of sustained discharge resembling a focal ictal discharge; the second type (asterisks) occurs in all areas and is characterized by slow interictal spikes; the third type (arrows) consists of continuous fast interictal-like events that are recorded in the CA3 subfield. Expanded traces of one fast and one slow interictal spike are shown in panels (b) and (c), respectively. (B): In panel (a), simultaneous field potential recordings obtained from the anterior and posterior portions of the piriform cortex in a sagittal slice; electrodes were positioned in layers I, II and III, as shown in the slice drawing. Note that both focal ictal discharges (grey lines) and interictal spikes (asterisks) occur spontaneously; two interictal spikes are expanded in panels $(\mathbf{b}, \mathbf{c})$. Panels shown in $(\mathbf{A}, \mathbf{B})$ are modified from the studies by Avoli et al. [36] and by Panuccio et al. [37], respectively.

HFOs are not visible in standard field potential recordings and can only be extracted by amplifying the appropriately filtered signal. Pathological HFOs - which have been categorized according to their frequency as ripples (80-200 Hz) and fast ripples (250-500 Hz) - presumably reflect the activity of dysfunctional neural networks sustaining epileptic discharges, and they are now considered better markers than interictal spikes to identify seizure onset zones [44]. Several mechanisms may contribute to HFOs, and their exact roles remain elusive; however, it has been proposed that ripples may represent population-inhibitory postsynaptic potentials generated by principal neurons entrained by synchronously active interneuron networks [45,46]; in contrast, fast ripples should mirror in-phase or out-of-phase synchronous firing of abnormally active principal cells, and they would be independent of inhibitory neurotransmission [47-51]. 
During the last few years, we have employed extended rat brain slices-which included either the piriform cortex or the entorhinal cortex-to analyze the ability of the neurosteroid THDOC to influence the epileptiform activity induced by $4 \mathrm{AP}$ in non-epileptic control (NEC) (Figure 2A) and pilocarpine-treated animals (Figure 2B) [15,17]. THDOC is known to enhance brain inhibition [52] and to induce anticonvulsant effects in vivo $[10,19,53,54]$ (see also Section 3). As shown in Figure 2A,C,D, THDOC decreased the duration of the ictal discharges while prolonging the interictal spikes recorded in brain slices that had been obtained from NEC rats and included the piriform cortex or the entorhinal cortex. In addition, when analyzing ripples and fast ripples associated to 4AP-induced ictal discharges in the piriform (Figure 3A) and entorhinal cortex (Figure 3B), we found in these experiments that THDOC decreased the occurrence of fast ripples that were associated with interictal spikes (Figure 3C). THDOC, however, induced in pilocarpine-treated animals a significant increase of ripples in the piriform and entorhinal cortices and a significant increase of fast ripples in the piriform cortex (Figure 3C,D). Overall, these results demonstrate that THDOC plays a modulatory role on the epileptiform synchronization and that its effects are structure-dependent and more pronounced in epileptic than in NEC tissue.
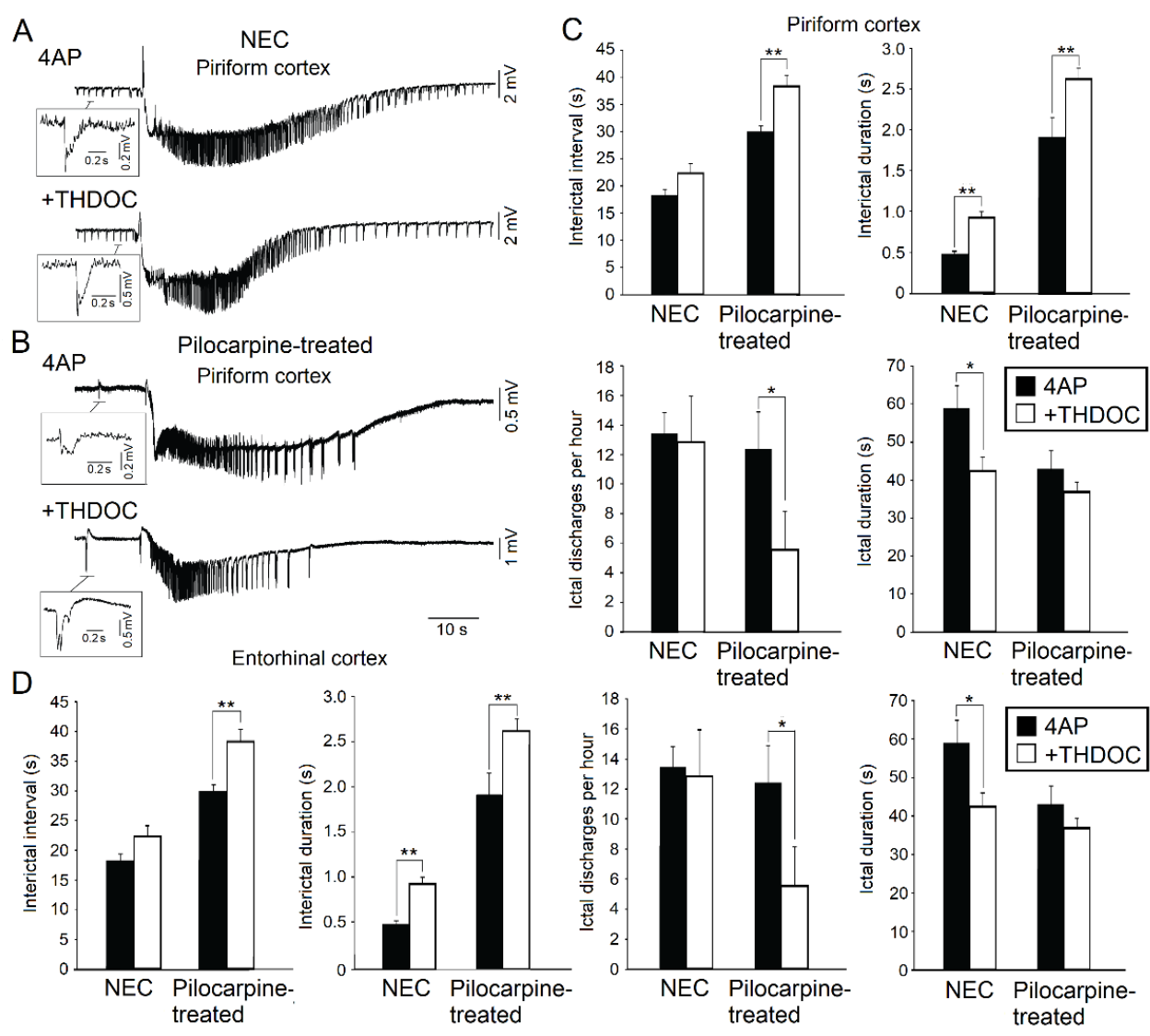

Figure 2. (A): Effects induced by allotetrahydrodeoxycorticosterone (THDOC) on the 4AP-induced epileptiform activity generated in vitro by the piriform cortex obtained from non-epileptic control (NEC) rodents. Note that both interictal (enlarged sample) and ictal discharges can be recorded during application of 4AP and following the addition of THDOC. (B): 4AP-induced interictal and ictal discharges recorded from the piriform cortex of brain slices obtained from epileptic (Pilocarpine-treated) rodents in 4AP and following bath application of THDOC. (C): Quantification of the interictal events and ictal events recorded from the piriform cortex during 4AP application and after application of THDOC in brain slices obtained from NEC and pilocarpine-treated animals. (D): Quantification of the interictal and ictal events recorded from the entorhinal cortex during 4AP application and after application of THDOC in brain slices obtained from NEC and pilocarpine-treated animals. * indicates $p<0.05 ;{ }^{* *}$ indicates $p<0.01$. Panels shown in this figure are modified from the study by Shiri et al. [17]. 


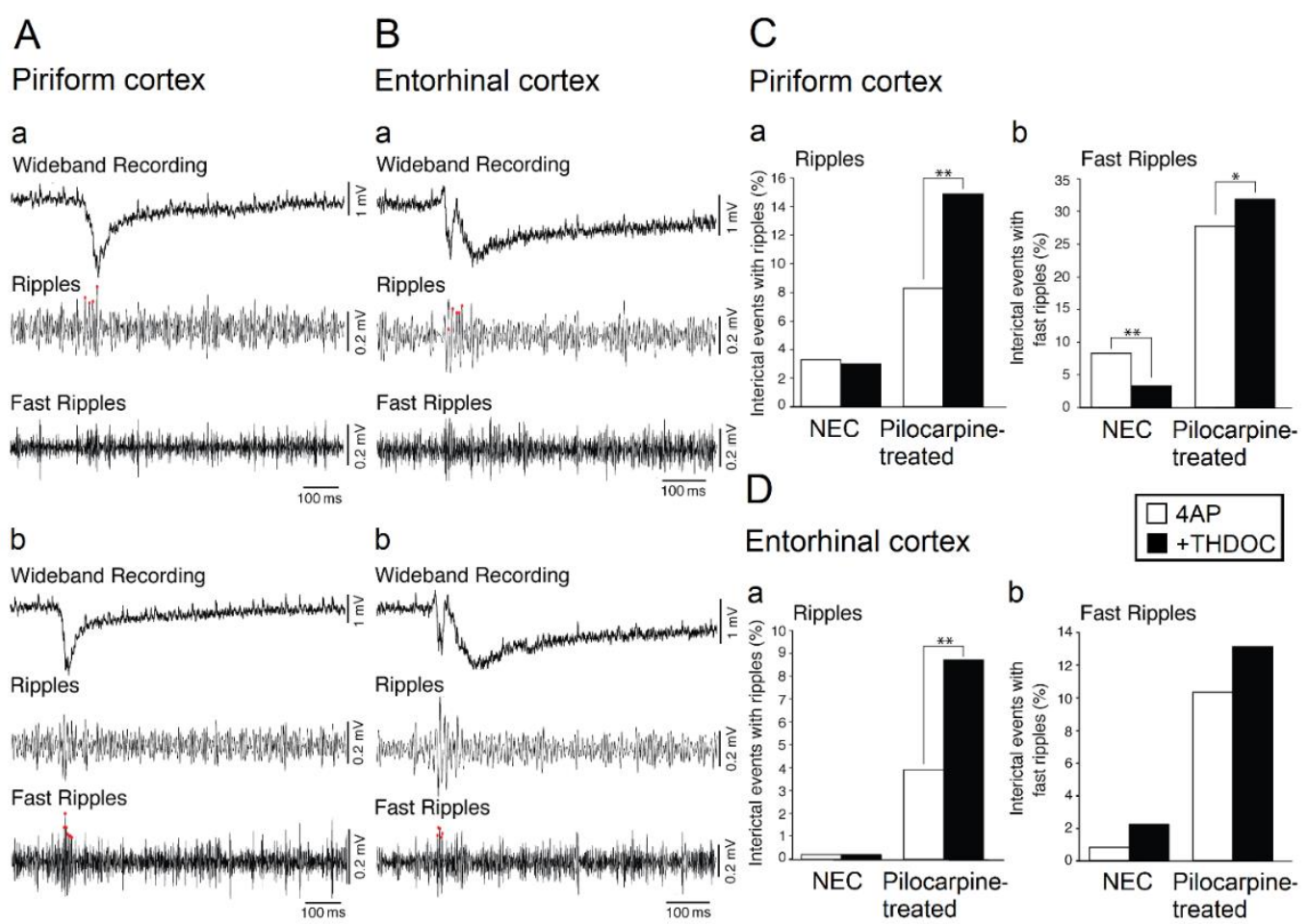

Figure 3. HFOs associated with 4AP-induced interictal discharges occurring in the piriform (A) and entorhinal cortex (B); field potential recordings showing interictal events co-occurring with ripples and fast ripples are shown in panels $(\mathbf{a}, \mathbf{b})$, respectively. $(\mathbf{C}, \mathbf{D})$ : Quantification of the effects induced by THDOC on the ripples and fast ripples associated with 4AP-induced interictal events recorded from the piriform and entorhinal cortex of brain slices that were obtained from NEC and pilocarpine-treated rats. Note that THDOC increases the association of ripples with the interictal discharges occurring in both the piriform and entorhinal cortex of epileptic animals; THDOC also decreases and increases fast ripple occurrence in the piriform cortex of NEC and epileptic brain slices, respectively, but does not induce any significant change in fast ripples recorded from the entorhinal cortex. ${ }^{*}$ indicates $p<0.05$; ${ }^{* *}$ indicates $p<0.01$. Panels shown in this figure are modified from the study by Shiri et al. [17].

Herrington et al. [15] also found that THDOC can induce a dose-dependent decrease in the duration of the fast interictal events recorded from the CA3 subfield of the hippocampus; in contrast, the duration of the slow interictal spikes increased. Moreover, THDOC potentiated the slow interictal events that were recorded during a pharmacological blockade of glutamatergic transmission but had no effect on the interictal pattern that was generated during $\mathrm{GABA}_{\mathrm{A}}$ receptor antagonism. Therefore, these results suggest that potentiation of $\mathrm{GABA}_{\mathrm{A}}$ receptor-mediated signaling by THDOC differentially affects slow and fast interictal discharges. It was also found in this study [15] that HFOs were modulated by THDOC. In addition, when it was applied to 4AP-treated slices, THDOC led to an increase in ripple occurrence without any concomitant change in fast ripple activity, thus indicating that it increases GABA-receptor mediated function. As already mentioned, ripples presumably reflect the synchronous activity of GABAergic interneurons [46,55-57]. Note that the amplitude of ripples and fast ripples associated with the interictal spikes was also increased by THDOC; such effects could reflect the increased recruitment of synchronized pyramidal cells [15], although this hypothesis needs to be confirmed.

\section{Effects in Animal Models of Mesial Temporal Lobe Epilepsy In Vivo}

In animal models of focal epilepsy, $\mathrm{GABA}_{\mathrm{A}}$ receptor expression is extensively altered in a regionand neuronal-subtype-specific manner, which ultimately affects both phasic and tonic inhibitory currents $[58,59]$. For instance, following the induction of temporal lobe epilepsy in rats with continual 
hippocampal stimulation, the $\delta$ subunit-containing receptor expression is reduced in dentate gyrus granule cells, while there is an increase in the expression of $\alpha_{4} \gamma_{2}$-containing subunits [60]. The increase in $\alpha_{4} \gamma_{2}$-containing subunits presumably acts as a compensatory mechanism for the initial reduction in tonic inhibition. Similar findings were also observed in pilocarpine-treated mice, but these authors also found that $\delta$ subunit containing receptor expression increased in hippocampal interneurons [61]. Furthermore, dentate gyrus granule cells exhibit an increase in the expression of synaptic GABA receptors, which is coupled with a reduced sensitivity to benzodiazepines [62]. The down-regulation of the $\delta$ subunit-containing receptors suggests that temporal lobe epilepsy may be associated with reduced levels of neurosteroid sensitivity [62]. Additional mechanisms in epileptic animals that can alter neurosteroid sensitivity include a loss of GABAergic neurons in the subiculum $[63,64]$ and a shift in inhibition such that principal cell GABAergic input is reduced, while interneuronal GABAergic input is enhanced in the piriform cortex [65].

Høgskilde et al. [66] were the first to demonstrate in vivo that a systemic pre-administration of pregnanolone could protect against acute seizures induced with several chemoconvulsants, such as pentetrazole, bicuculline, picrotoxin and strychnine. Similar results were obtained by Belelli et al. [67], who also reported that more potent anti-ictogenic effects were obtained when allopregnanolone was administered before the $\mathrm{GABA}_{\mathrm{A}}$ receptor antagonist bicuculline. Allopregnanolone was, however, ineffective in the maximal electroshock model and against strychnine-induced seizures, as later confirmed by Kokate et al. [68]. Further studies also showed that allopregnanolone induces a dose-dependent protection against seizures in the $6 \mathrm{~Hz}$ and pentylenetetrazole model, as well as partial protection against NMDA-induced seizures [68-70].

The anti-ictogenic properties of neurosteroids are not only observed in acute seizure models, but also in chronic animal models of MTLE, such as in the pilocarpine and kainic acid model. Pilocarpine is a cholinergic muscarinic agonist that when systemically injected in rodents, induces a status epilepticus (SE) that is followed by a latent period-during which no seizures are observed-and then by recurrent, spontaneous non-convulsive and convulsive seizures [71,72]. Kainic acid-which is a cyclic analog of L-glutamate and an agonist of the ionotropic kainate receptor-when administered locally or systemically in rodents, also induces an SE that is followed by a latent period and then by the occurrence of spontaneous focal seizures that can become secondarily generalized [73-76]. Kokate et al. [70] have shown that allopregnanolone and THDOC can prevent the development of pilocarpine-induced SE in rodents. Furthermore, when administered $15 \mathrm{~min}$ after the onset of SE, pregnanolone completely abolished ictal activity. Saporito et al. [77] recently reported that such effects can be observed when allopregnanolone or ganaxolone (the $3 \beta$-methylated synthetic analog of allopregnanolone) are administered $15 \mathrm{~min}$ after SE onset in the lithium-pilocarpine model. Ganaxolone had similar anti-ictogenic properties when administered 60 min after SE onset, whereas only transient effects were observed with allopregnanolone [77].

Kokate et al. have also reported that pregnanolone and THDOC provide protection against the development of kainic acid-induced SE in mice [70]. However, neurosteroids had less potent anti-ictogenic effects in this model than in the pilocarpine model. According to these investigators, this difference should be due to the prolonged duration of the kainic acid-induced SE as compared to pilocarpine-induced SE; in line with their view, they found that a second administration of the investigated neurosteroid $1 \mathrm{~h}$ after the first dose was needed to obtain a complete anti-ictogenic effect in the kainic acid model [70].

Although neurosteroid levels can significantly modulate SE in animal models of MTLE, it was unclear until a few years ago whether they also display any relationships with the duration of the latent period and the occurrence of spontaneous seizures. Evidence obtained by Biagini et al. [78] now suggests that the duration of the latent period, as well as P450scc induction, is indeed increased in animals that have endured prolonged pilocarpine-induced SE. However, when neurosteroid synthesis is blocked with finasteride, the duration of the latent period is decreased [78], suggesting that by increasing GABA-mediated inhibition, neurosteroids can delay the development of a chronic epileptic 
condition, as was proposed before in the kindling model of epileptogenesis [79]. The same group then performed further analyses of P450scc immunoreactivity in the hippocampus of pilocarpine-treated rodents and found that it is expressed in several glial cells including astrocytes, oligodendrocytes and microglia [80]. In the same study, they also found that inhibition of neurosteroids with a daily administration of finasteride between day 4 and day 28 after SE could accelerate the development of spontaneous seizures, but only in animals that experienced an SE that lasted for more than $3 \mathrm{~h}$ and that exhibited significant increases of P450scc induction. In line with these findings, Joshi et al. [81] used the lithium-pilocarpine model to demonstrate that a single administration of finasteride on the fourth day after a $2 \mathrm{~h} \mathrm{SE}$ is sufficient to decrease the duration of the latent period; according to these authors, this suggests that inhibition of neurosteroids must be performed at the time of down-regulation of $\delta$-GABA receptor expression, which occurs between SE and the onset of spontaneous seizures.

Since allopregnanolone is a positive allosteric modulator of synaptic and extrasynaptic modulator of $\mathrm{GABA}_{\mathrm{A}}$ receptors, its administration could functionally reverse the GABAergic deficit that may occur after SE. Lévesque et al. [14], therefore, assessed whether its administration during the latent phase could modulate spontaneous seizures in the pilocarpine rat model of MTLE. In their study, allopregnanolone was administered with a subcutaneous pump for 12 consecutive days starting 1 day after SE. Compared to the untreated group, in which $67 \%$ of them became epileptic, only $29 \%$ of allopregnanolone-treated animals were epileptic. These anti-epileptogenic effects were associated to significantly lower rates of interictal spikes in the CA3 and entorhinal cortex of non-epileptic allopregnanolone-treated animals compared to the untreated group (Figure 4A-C). Rates of interictal spikes with fast ripples (Figure 4D) were also significantly lower in the allopregnanolone-treated group compared to the untreated group (Figure 4E), whereas rates of interictal spikes with ripples (Figure 4D) were not significantly different between groups (Figure 4F). Interestingly, the effects induced by allopregnanolone were similar to those observed with the anti-epileptic drugs levetiracetam and lacosamide in the pilocarpine model of MTLE [82,83], confirming the potential of GABA $_{\mathrm{A}}$ receptor modulating neurosteroids in the treatment of epilepsy.

Endogenous levels of allopregnanolone and pregnanolone in the brain of rats that have been treated with kainic acid to induce an SE are also significantly modulated by spontaneous seizures. Lucchi et al. [84] recently observed reduced levels of allopregnanolone and pregnanolone in the hippocampus of epileptic animals 9 weeks after SE. Moreover, linear regression analyses revealed a significant positive correlation between endogenous levels of allopregnanolone and seizure frequency in the hippocampus (higher seizure rates of seizures were associated with increased levels of allopregnanolone), whereas this correlation was not observed in the neocortex. No significant correlations were observed between endogenous levels of pregnanolone and the frequency of spontaneous seizures and no alterations in circulating levels of allopregnanolone and pregnanolone were observed. It was, therefore, hypothesized that focal allopregnanolone synthesis in the hippocampus is increased in the presence of seizures as a compensatory mechanism, but that it fails in restoring levels of this neurosteroid. 
A

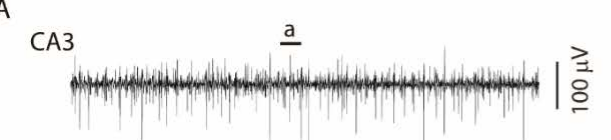

EC

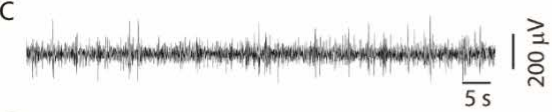

a

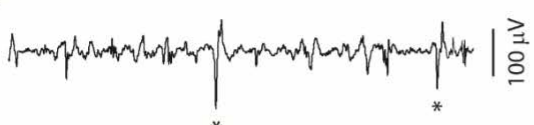

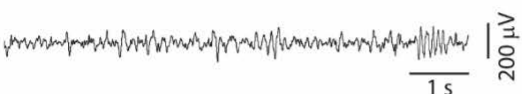

C

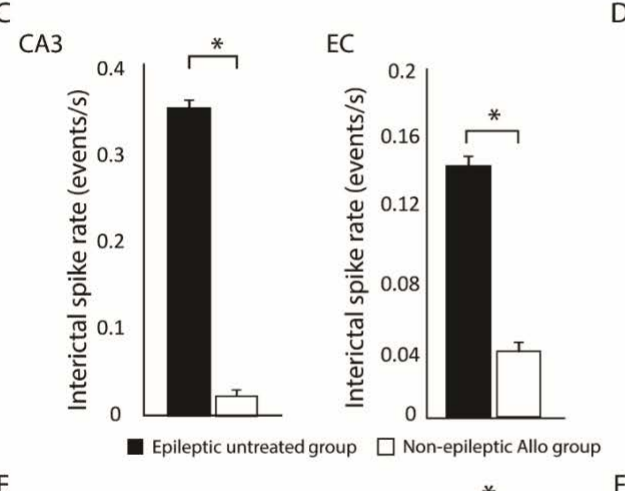

E

$\mathrm{CA} 3$

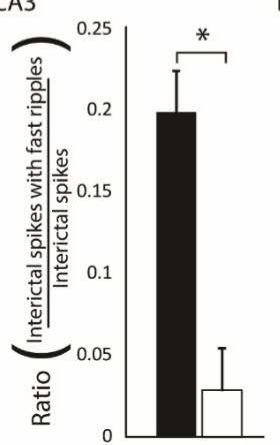

EC

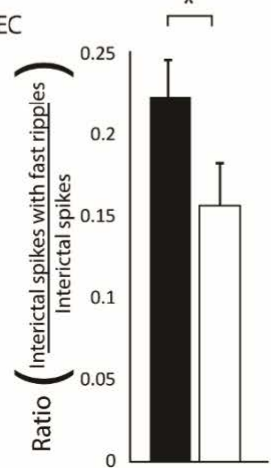

B

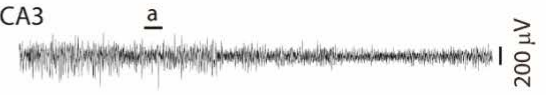

EC

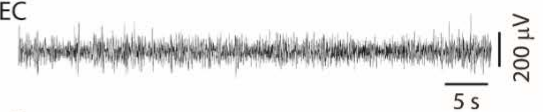

a

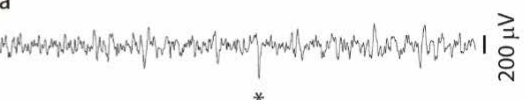

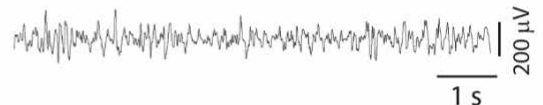

$D_{\bar{N} 500}$ Ripples $(80-200 \mathrm{~Hz})$
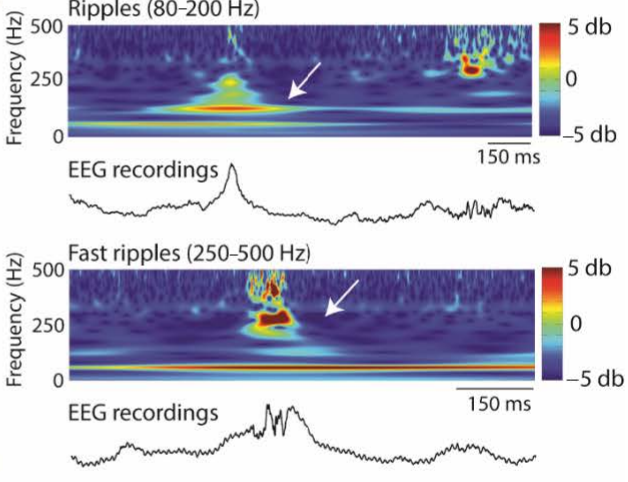

CA3

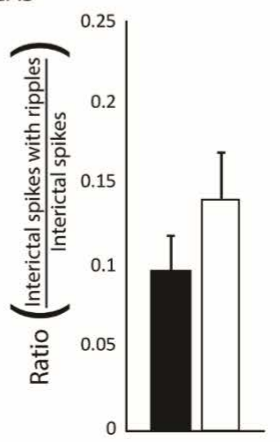

EC

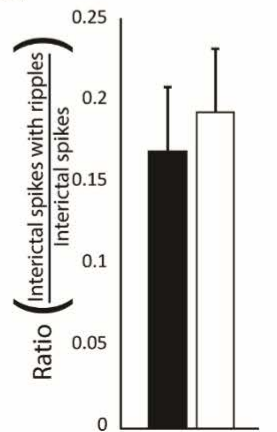

Figure 4. (A): Representative EEG recordings from the CA3 region of the hippocampus and the entorhinal cortex (EC) of an epileptic untreated animal. (B): Representative recordings in an epileptic animal that was treated with allopregnanolone. Insets (a) show interictal spikes (asterisks) on a lower timescale. (C): Bar graphs showing rates of interictal spikes in the epileptic untreated and non-epileptic allopregnanolone-treated group. Rates of interictal spikes in CA3 and EC were significantly lower in the non-epileptic allopregnanolone-treated group compared to the epileptic untreated group $\left({ }^{*} p<0.05\right)$. (D): Example of a ripple $(80-200 \mathrm{~Hz})$ and a fast ripple $(250-500 \mathrm{~Hz})$ that occurred in association with an interictal spike, in an epileptic untreated animal. The wavelet analysis is shown to illustrate ripples and fast ripples (white arrows). (E): Bar graph showing ratios of interictal spikes with fast ripples on the total number of interictal spikes. In both CA3 and EC, rates of interictal spikes with fast ripples occurred at significantly lower rates in the non-epileptic allopregnanolone-treated group compared to the epileptic untreated group $\left.{ }^{*} p<0.05\right)$. (F): Bar graph showing ratios of interictal spikes with ripples on the total number of interictal spikes. No significant differences were observed between groups. Panels were modified from the study of Lévesque et al. [14].

\section{Human Studies}

The possible therapeutic use of neurosteroids for epilepsy was first explored in pediatric patients treated with the methylated analog of allopregnanolone, ganaxolone [85]. These authors examined 15 patients within the range of 5-15 years of age, suffering from drug-resistant epilepsy of various 
types; eight of them concluded the trial, at the end of which beneficial effects were observed in six patients. This pilot study was then followed by another one performed in adults with partial-onset seizures that were poorly controlled by antiepileptic drugs [86]. In this study, 131 patients completed the protocol (86 maintained on ganaxolone) and a reduction of about $11 \%$ in the seizure frequency was observed with ganaxolone. The most common adverse events were dizziness, fatigue and somnolence, found in approximately $15 \%$ of cases. Additionally, in view of the reduction in allopregnanololone and other steroid levels in patients with protocadherin 19 (PCDH19)—female limited epilepsy [87], trial is currently ongoing to evaluate if ganaxolone may be beneficial in patients with this rare neurological disorder [88]. However, caution on the effectiveness of the use of allopregnanolone analogues has been raised by a study on post mortem neocortical tissue obtained from children with epilepsy, in which authors found an altered composition of $\mathrm{GABA}_{\mathrm{A}}$ receptors leading to reduced sensitivity to neurosteroids [89]. Therefore, these results suggest that children could be unresponsive to allopregnanolone analogues.

Unsatisfactorily, the allopregnanolone analog brenaxolone has been tested in patients with refractory or super-refractory SE [90]. After having successfully passed a phase I/II trial [91], a phase III trial did not find any beneficial effect of brexanolone (reported in Rossetti et al. [90]). However, Meletti et al. [92,93] found a marked reduction in progesterone, $5 \alpha$-dihydroprogesterone, allopregnanolone and pregnanolone levels in the cerebrospinal fluid obtained by patients with SE, thus suggesting that administration of allopregnanolone or the analogs alone could be insufficient to reach an adequate compensation for the reported defect in various neurosteroid levels. In this regard, a more effective approach to re-establish normal levels of anticonvulsant neurosteroids should be made available. Such a goal could be possibly achieved by using trilostane, an inhibitor of peripheral conversion of pregnenolone to progesterone, which was found to increase the cerebral levels of different neurosteroids [94,95]. Recently, pretreatment with trilostane was shown to increase the neocortical and hippocampal levels of pregnenolone, progesterone, $5 \alpha$-dihydroprogesterone and allopregnanolone, leading to the reduction in convulsive seizure duration in rats with kainic acid-induced SE [96].

Finally, progesterone is known to be effective in catamenial epilepsy, i.e., epileptic women who experience perimenstrual seizure exacerbation [97]. This effect could be related to the conversion of progesterone to allopregnanolone, as suggested by a case report in which a woman, cured with progesterone, developed refractoriness to antiepileptic drugs when she was treated with finasteride [98]. However, the appearance of resistance to antiepileptic drugs has been also reported in a woman who was treated with finasteride but did not receive progesterone as an add-on drug. This finding suggests that allopregnanolone levels might influence the response to the antiepileptic treatment [99].

\section{Conclusions}

We have reviewed here some experimental and clinical studies that were aimed at establishing the involvement of neurosteroids in the context of focal epileptic disorders. Clearly, the modulatory effects exerted by these compounds depends on their class (e.g., sulfated vs. nonsulfated), the subunit composition of the neurotransmitter receptors as well as the pathophysiological mechanisms that underlie specific epileptic disorders. For instance, much of the experimental evidence suggests that the ability of neurosteroids to influence neuronal excitability resides primarily in the enhancement of $\mathrm{GABA}_{\mathrm{A}}$ receptor function. On the other hand, this physiological characteristic may result in opposite effects, depending on the contribution of GABAergic mechanisms to epileptiform synchronization [100]. Finally, it remains to be firmly established whether neurosteroids or their analogues can prevent the development of a chronic epileptic condition (i.e., whether they can successfully halt epileptogenesis).

Author Contributions: M.L., G.B. and M.A. all contributed to the writing of this paper and to some experiments that were presented in this review. All authors have read and agreed to the published version of the manuscript.

Funding: This research was funded by the Canadian Institutes of Health Research (CIHR Operating Grants 8109, 74609 and 130328) and the Savoy Foundation.

Conflicts of Interest: The authors declare no conflict of interest. 


\section{Abbreviations}

$\begin{array}{ll}\text { 4AP } & \text { 4-aminopyridine } \\ \text { P450scc } & \text { P450 cholesterol side chain cleavage } \\ \text { HFOs } & \text { high-frequency oscillations } \\ \text { MTLE } & \text { mesial temporal lobe epilepsy } \\ \text { NEC } & \text { non-epileptic control } \\ \text { PCDH19 } & \text { Protocadherin 19 } \\ \text { PTX } & \text { picrotoxin } \\ \text { SE } & \text { status epilepticus } \\ \text { THDOC } & \text { Allotetrahydrodeoxycorticosterone }\end{array}$

\section{References}

1. Akk, G.; Covey, D.F.; Evers, A.S.; Steinbach, J.H.; Zorumski, C.F.; Mennerick, S. The influence of the membrane on neurosteroid actions at $\mathrm{GABA}_{\mathrm{A}}$ receptors. Psychoneuroendocrinology 2009, 34 (Suppl. S1), S59-S66. [CrossRef]

2. Mellon, S.H.; Griffin, L.D. Neurosteroids: Biochemistry and clinical significance. Trends Endocrinol. Metab. 2002, 13, 35-43. [CrossRef]

3. MacKenzie, G.; Maguire, J. Neurosteroids and GABAergic signaling in health and disease. Biomol. Concepts 2013, 4, 29-42. [CrossRef]

4. Reddy, D.S. Neurosteroids: Endogenous Role in the Human Brian and Therapeutic Potentials. Prog. Brain Res. 2010, 186, 113-137. [CrossRef] [PubMed]

5. Majewska, M.D. Neurosteroids: Endogenous bimodal modulators of the GABA $\mathrm{A}$ receptor. Mechanism of action and physiological significance. Prog. Neurobiol. 1992, 38, 379-395. [CrossRef]

6. Park-Chung, M.; Malayev, A.; Purdy, R.H.; Gibbs, T.T.; Farb, D.H. Sulfated and unsulfated steroids modulate $\gamma$-aminobutyric acid(A) receptor function through distinct sites. Brain Res. 1999, 830, 72-87. [CrossRef]

7. Sousa, A.; Ticku, M.K. Interactions of the neurosteroid dehydroepiandrosterone sulfate with the GABA(A) receptor complex reveals that it may act via the picrotoxin site. J. Pharmacol. Exp. Ther. 1997, 282, 827-833. [PubMed]

8. Wu, F.S.; Gibbs, T.T.; Farb, D.H. Pregnenolone sulfate: A positive allosteric modulator at the N-methyl-D-aspartate receptor. Mol. Pharmacol. 1991, 40, 333-336.

9. Belelli, D.; Lambert, J.J. Neurosteroids: Endogenous regulators of the GABA(A) receptor. Nat. Rev. Neurosci. 2005, 6, 565-575. [CrossRef]

10. Reddy, D.S. Role of anticonvulsant and antiepileptogenic neurosteroids in the pathophysiology and treatment of epilepsy. Front. Endocrin. 2011, 2, 38. [CrossRef]

11. Reddy, D.S.; Rogawski, M.A. Neurosteroids-Endogenous Regulators of Seizure Susceptibility and Role in the Treatment of Epilepsy. In Jasper's Basic Mechanisms of the Epilepsies; Noebels, J.L., Avoli, M., Rogawski, M.A., Olsen, R.W., Delgado-Escueta, A.V., Eds.; National Center for Biotechnology Information (US): Bethesda, MD, USA, 2012.

12. Biagini, G.; Panuccio, G.; Avoli, M. Neurosteroids and epilepsy. Curr. Opin. Neurol. 2010, 23, $170-176$. [CrossRef] [PubMed]

13. Reddy, D.S.; Rogawski, M.A. Neurosteroids as endogenous regulators of seizure susceptibility and use in the treatment of epilepsy. Epilepsia 2010, 51, 84. [CrossRef] [PubMed]

14. Lévesque, M.; Herrington, R.; Leclerc, L.; Rogawski, M.A.; Avoli, M. Allopregnanolone decreases interictal spiking and fast ripples in an animal model of mesial temporal lobe epilepsy. Neuropharmacology 2017. [CrossRef] [PubMed]

15. Herrington, R.; Lévesque, M.; Avoli, M. Neurosteroids differentially modulate fast and slow interictal discharges in the hippocampal CA3 area. Eur. J. Neurosci. 2015, 41, 379-389. [CrossRef]

16. Herrington, R.; Lévesque, M.; Avoli, M. Neurosteroids modulate epileptiform activity and associated high frequency oscillations in the piriform cortex. Neuroscience 2013. [CrossRef]

17. Shiri, Z.; Herrington, R.; Lévesque, M.; Avoli, M. Neurosteroidal modulation of in vitro epileptiform activity is enhanced in pilocarpine-treated epileptic rats. Neurobiol. Dis. 2015, 78, 24-34. [CrossRef] 
18. Reddy, D.S. Pharmacology of Endogenous Neuroactive Steroids. Crit. Rev. Neurobiol. 2004, 15, $197-234$. [CrossRef]

19. Rupprecht, R.; Hauser, C.A.E.; Trapp, T.; Holsboer, F. Neurosteroids: Molecular mechanisms of action and psychopharmacological significance. J. Steroid Biochem. Mol. Biol. 1996, 56, 163-168. [CrossRef]

20. Belelli, D.; Casula, A.; Ling, A.; Lambert, J.J. The influence of subunit composition on the interaction of

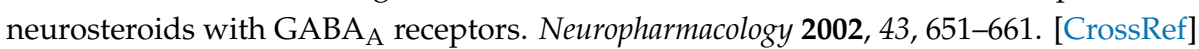

21. Gangisetty, O.; Reddy, D.S. Neurosteroid withdrawal regulates GABA-A receptor $\alpha 4$-subunit expression and seizure susceptibility by activation of progesterone receptor-independent early growth response factor-3 pathway. Neuroscience 2010, 170, 865-880. [CrossRef]

22. Kaminski, R.M.; Marini, H.; Kim, W.-J.; Rogawski, M.A. Anticonvulsant Activity of Androsterone and Etiocholanolone. Epilepsia 2005, 46, 819-827. [CrossRef] [PubMed]

23. Agís-Balboa, R.C.; Pinna, G.; Zhubi, A.; Maloku, E.; Veldic, M.; Costa, E.; Guidotti, A. Characterization of brain neurons that express enzymes mediating neurosteroid biosynthesis. Proc. Natl. Acad. Sci. USA 2006, 103, 14602-14607. [CrossRef] [PubMed]

24. Strömstedt, M.; Waterman, M.R. Messenger RNAs encoding steroidogenic enzymes are expressed in rodent brain. Brain Res. Mol. Brain Res. 1995, 34, 75-88. [CrossRef]

25. Majewska, M.D.; Harrison, N.L.; Schwartz, R.D.; Barker, J.L.; Paul, S.M. Steroid hormone metabolites are barbiturate-like modulators of the GABA receptor. Science 1986, 232, 1004-1007. [CrossRef] [PubMed]

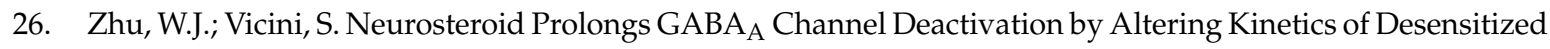
States. J. Neurosci. 1997, 17, 4022-4031. [CrossRef]

27. Wohlfarth, K.M.; Bianchi, M.T.; Macdonald, R.L. Enhanced neurosteroid potentiation of ternary GABA(A) receptors containing the delta subunit. J. Neurosci. 2002, 22, 1541-1549. [CrossRef]

28. Mihalek, R.M.; Banerjee, P.K.; Korpi, E.R.; Quinlan, J.J.; Firestone, L.L.; Mi, Z.-P.; Lagenaur, C.; Tretter, V.; Sieghart, W.; Anagnostaras, S.G.; et al. Attenuated sensitivity to neuroactive steroids in $\gamma$-aminobutyrate type A receptor delta subunit knockout mice. Proc. Natl. Acad. Sci. USA 1999, 96, 12905-12910. [CrossRef]

29. Glykys, J.; Mody, I. Activation of GABA A Receptors: Views from Outside the Synaptic Cleft. Neuron 2007, 56, 763-770. [CrossRef]

30. Hosie, A.M.; Wilkins, M.E.; da Silva, H.M.A.; Smart, T.G. Endogenous neurosteroids regulate GABA $_{A}$ receptors through two discrete transmembrane sites. Nature 2006, 444, 486-489. [CrossRef]

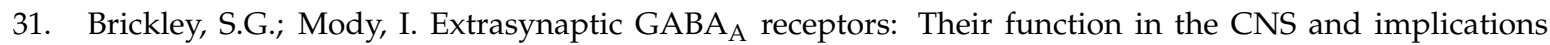
for disease. Neuron 2012, 73, 23-34. [CrossRef]

32. Salazar, P.; Tapia, R.; Rogawski, M.A. Effects of neurosteroids on epileptiform activity induced by picrotoxin and 4-aminopyridine in the rat hippocampal slice. Epilepsy Res. 2003, 55, 71-82. [CrossRef]

33. Avoli, M.; D'Antuono, M.; Louvel, J.; Köhling, R.; Biagini, G.; Pumain, R.; D'Arcangelo, G.; Tancredi, V. Network and pharmacological mechanisms leading to epileptiform synchronization in the limbic system in vitro. Prog. Neurobiol. 2002, 68, 167-207. [CrossRef]

34. Avoli, M.; de Curtis, M. GABAergic synchronization in the limbic system and its role in the generation of epileptiform activity. Prog. Neurobiol. 2011, 95, 104-132. [CrossRef] [PubMed]

35. Perreault, P.; Avoli, M. 4-aminopyridine-induced epileptiform activity and a GABA-mediated long-lasting depolarization in the rat hippocampus. J. Neurosci. 1992, 12, 104-115. [CrossRef]

36. Avoli, M.; Barbarosie, M.; Lücke, A.; Nagao, T.; Lopantsev, V.; Köhling, R. Synchronous GABA-Mediated Potentials and Epileptiform Discharges in the Rat Limbic System In Vitro. J. Neurosci. 1996, 16, 3912-3924. [CrossRef]

37. Panuccio, G.; Sanchez, G.; Lévesque, M.; Salami, P.; de Curtis, M.; Avoli, M. On the ictogenic properties of the piriform cortex in vitro. Epilepsia 2012, 53, 459-468. [CrossRef]

38. Sudbury, J.R.; Avoli, M. Epileptiform synchronization in the rat insular and perirhinal cortices in vitro. Eur. J. Neurosci. 2007, 26, 3571-3582. [CrossRef]

39. Panuccio, G.; Curia, G.; Colosimo, A.; Cruccu, G.; Avoli, M. Epileptiform synchronization in the cingulate cortex. Epilepsia 2009, 50, 521-536. [CrossRef]

40. Bragin, A.; Engel, J., Jr.; Wilson, C.L.; Fried, I.; Mathern, G.W. Hippocampal and entorhinal cortex high-frequency oscillations $(100-500 \mathrm{~Hz})$ in human epileptic brain and in kainic acid-Treated rats with chronic seizures. Epilepsia 1999, 40, 127-137. [CrossRef] 
41. Staba, R.J.; Wilson, C.L.; Bragin, A.; Fried, I.; Engel, J., Jr. Quantitative analysis of high-frequency oscillations (80-500 Hz) recorded in human epileptic hippocampus and entorhinal cortex. J. Neurophysiol. 2002, 88, 1743-1752. [CrossRef]

42. Jirsch, J.D.; Urrestarazu, E.; LeVan, P.; Olivier, A.; Dubeau, F.; Gotman, J. High-frequency oscillations during human focal seizures. Brain 2006, 129, 1593-1608. [CrossRef] [PubMed]

43. Lévesque, M.; Bortel, A.; Gotman, J.; Avoli, M. High-frequency (80-500 Hz) oscillations and epileptogenesis in temporal lobe epilepsy. Neurobiol. Dis. 2011, 42, 231-241. [CrossRef] [PubMed]

44. Jefferys, J.G.R.; Menendez de la Prida, L.; Wendling, F.; Bragin, A.; Avoli, M.; Timofeev, I.; Lopes da Silva, F.H. Mechanisms of physiological and epileptic HFO generation. Prog. Neurobiol. 2012, 98, 250-264. [CrossRef] [PubMed]

45. Buzsáki, G.; Chrobak, J.J. Temporal structure in spatially organized neuronal ensembles: A role for interneuronal networks. Curr. Opin. Neurobiol. 1995, 5, 504-510. [CrossRef]

46. Ylinen, A.; Bragin, A.; Nadasdy, Z.; Jando, G.; Szabo, I.; Sik, A.; Buzsaki, G. Sharp wave-associated high-frequency oscillation $(200 \mathrm{~Hz})$ in the intact hippocampus: Network and intracellular mechanisms. J. Neurosci. 1995, 15, 30-46. [CrossRef] [PubMed]

47. Bragin, A.; Benassi, S.K.; Kheiri, F.; Engel, J., Jr. Further evidence that pathologic high-frequency oscillations are bursts of population spikes derived from recordings of identified cells in dentate gyrus. Epilepsia 2011, 52, 45-52. [CrossRef] [PubMed]

48. Dzhala, V.I.; Staley, K.J. Mechanisms of Fast Ripples in the Hippocampus. J. Neurosci. 2004, 24, 8896-8906. [CrossRef]

49. Engel, J., Jr.; Bragin, A.; Staba, R.; Mody, I. High-frequency oscillations: What is normal and what is not? Epilepsia 2009, 50, 598-604. [CrossRef]

50. Foffani, G.; Uzcategui, Y.G.; Gal, B.; Menendez de la Prida, L. Reduced Spike-Timing Reliability Correlates with the Emergence of Fast Ripples in the Rat Epileptic Hippocampus. Neuron 2007, 55, 930-941. [CrossRef]

51. Ibarz, J.M.; Foffani, G.; Cid, E.; Inostroza, M.; de la Prida, L.M. Emergent Dynamics of Fast Ripples in the Epileptic Hippocampus. J. Neurosci. 2010, 30, 16249-16261. [CrossRef]

52. Teschemacher, A.; Zeise, M.L.; Holsboer, F.; Zieglgänsberger, W. The Neuroactive Steroid $5 \alpha$-Tetrahydrodeoxycorticosterone Increases GABAergic Postsynaptic Inhibition in Rat Neocortical Neurons in vitro. J. Neuroendocrinol. 1995, 7, 233-240. [CrossRef] [PubMed]

53. Stell, B.M.; Brickley, S.G.; Tang, C.Y.; Farrant, M.; Mody, I. Neuroactive steroids reduce neuronal excitability by selectively enhancing tonic inhibition mediated by? Subunit-containing GABA $\mathrm{A}$ receptors. Proc. Natl. Acad. Sci. USA 2003, 100, 14439-14444. [CrossRef] [PubMed]

54. Reddy, D.S. Role of neurosteroids in catamenial epilepsy. Epilepsy Res. 2004, 62, 99-118. [CrossRef]

55. Buzsaki, G.; Horvath, Z.; Urioste, R.; Hetke, J.; Wise, K. High-frequency network oscillation in the hippocampus. Science 1992, 256, 1025-1027. [CrossRef] [PubMed]

56. Demont-Guignard, S.; Benquet, P.; Gerber, U.; Biraben, A.; Martin, B.; Wendling, F. Distinct hyperexcitability mechanisms underlie fast ripples and epileptic spikes. Ann. Neurol. 2012, 71, 342-352. [CrossRef] [PubMed]

57. Wendling, F.; Bartolomei, F.; Mina, F.; Huneau, C.; Benquet, P. Interictal spikes, fast ripples and seizures in partial epilepsies-Combining multi-level computational models with experimental data. Eur. J. Neurosci. 2012, 36, 2164-2177. [CrossRef] [PubMed]

58. Fritschy, J.-M.; Kiener, T.; Bouilleret, V.; Loup, F. GABAergic neurons and GABAA-receptors in temporal lobe epilepsy. Neurochem. Int. 1999, 34, 435-445. [CrossRef]

59. Loup, F.; Wieser, H.G.; Yonekawa, Y.; Aguzzi, A.; Fritschy, J.M. Selective alterations in GABA receptor subtypes in human temporal lobe epilepsy. J. Neurosci. 2000, 20, 5401-5419. [CrossRef]

60. Rajasekaran, K.; Joshi, S.; Sun, C.; Mtchedlishvilli, Z.; Kapur, J. Receptors with low affinity for neurosteroids and GABA contribute to tonic inhibition of granule cells in epileptic animals. Neurobiol. Dis. 2010, 40, 490-501. [CrossRef]

61. Peng, Z.; Huang, C.S.; Stell, B.M.; Mody, I.; Houser, C.R. Altered Expression of the $\delta$ Subunit of the GABA Receptor in a Mouse Model of Temporal Lobe Epilepsy. J. Neurosci. 2004, 24, 8629-8639. [CrossRef]

62. Leroy, C.; Poisbeau, P.; Keller, A.F.; Nehlig, A. Pharmacological plasticity of GABA(A) receptors at dentate gyrus synapses in a rat model of temporal lobe epilepsy. J. Physiol. 2004, 557, 473-487. [CrossRef] [PubMed] 
63. de Guzman, P.; Inaba, Y.; Biagini, G.; Baldelli, E.; Mollinari, C.; Merlo, D.; Avoli, M. Subiculum network excitability is increased in a rodent model of temporal lobe epilepsy. Hippocampus 2006, 16, 843-860. [CrossRef] [PubMed]

64. Knopp, A.; Frahm, C.; Fidzinski, P.; Witte, O.W.; Behr, J. Loss of GABAergic neurons in the subiculum and its functional implications in temporal lobe epilepsy. Brain 2008, 131, 1516-1527. [CrossRef] [PubMed]

65. Gavrilovici, C.; D'Alfonso, S.; Dann, M.; Poulter, M.O. Kindling-induced alterations in GABA receptor-mediated inhibition and neurosteroid activity in the rat piriform cortex. Eur. J. Neurosci. 2006, 24, 1373-1384. [CrossRef]

66. Høgskilde, S.; Wagner, J.; Carl, P.; Anker, N.; Angelo, H.R.; Sørensen, M.B. Anticonvulsive properties of pregnanolone emulsion compared with althesin and thiopentone in mice. Br. J. Anaesth. 1988, 61, 462-467. [CrossRef]

67. Belelli, D.; Bolger, M.B.; Gee, K.W. Anticonvulsant profile of the progesterone metabolite 5 alpha-pregnan-3 alpha-ol-20-one. Eur. J. Pharmacol. 1989, 166, 325-329. [CrossRef]

68. Kokate, T.G.; Svensson, B.E.; Rogawski, M.A. Anticonvulsant activity of neurosteroids: Correlation with gamma-aminobutyric acid-evoked chloride current potentiation. J. Pharmacol. Exp. Ther. 1994, 270, 1223-1229.

69. Kaminski, R.M.; Livingood, M.R.; Rogawski, M.A. Allopregnanolone analogs that positively modulate GABA receptors protect against partial seizures induced by 6-Hz electrical stimulation in mice. Epilepsia 2004, 45, 864-867. [CrossRef]

70. Kokate, T.G.; Cohen, A.L.; Karp, E.; Rogawski, M.A. Neuroactive steroids protect against pilocarpine- and kainic acid-induced limbic seizures and status epilepticus in mice. Neuropharmacology 1996, 35, 1049-1056. [CrossRef]

71. Turski, L.; Ikonomidou, C.; Turski, W.A.; Bortolotto, Z.A.; Cavalheiro, E.A. Review: Cholinergic mechanisms and epileptogenesis. The seizures induced by pilocarpine: A novel experimental model of intractable epilepsy. Synapse 1989, 3, 154-171. [CrossRef]

72. Turski, W.A.; Cavalheiro, E.A.; Schwarz, M.; Czuczwar, S.J.; Kleinrok, Z.; Turski, L. Limbic seizures produced by pilocarpine in rats: Behavioural, electroencephalographic and neuropathological study. Behav. Brain Res. 1983, 9, 315-335. [CrossRef]

73. Ben-Ari, Y.; Lagowska, J.; Tremblay, E.; Le Gal La Salle, G. A new model of focal status epilepticus: Intra-amygdaloid application of kainic acid elicits repetitive secondarily generalized convulsive seizures. Brain Res. 1979, 163, 176-179. [CrossRef]

74. Ben-Ari, Y.; Lagowska, J. Epileptogenic action of intra-amygdaloid injection of kainic acid. Comptes Rendus Hebd. Séances Acad. Sci. Sér. Sci. Nat. 1978, 287, 813-816.

75. Cavalheiro, E.A.; Riche, D.A.; Le Gal La Salle, G. Long-term effects of intrahippocampal kainic acid injection in rats: A method for inducing spontaneous recurrent seizures. Electroencephalogr. Clin. Neurophysiol. 1982, 53, 581-589. [CrossRef]

76. Nadler, J.V. Kainic acid: Neurophysiological and neurotoxic actions. Life Sci. 1979, 24, 289-299. [CrossRef]

77. Saporito, M.S.; Gruner, J.A.; DiCamillo, A.; Hinchliffe, R.; Barker-Haliski, M.; White, H.S. Intravenously Administered Ganaxolone Blocks Diazepam-Resistant Lithium-Pilocarpine-Induced Status Epilepticus in Rats: Comparison with Allopregnanolone. J. Pharmacol. Exp. Ther. 2019, 368, 326-337. [CrossRef]

78. Biagini, G.; Baldelli, E.; Longo, D.; Pradelli, L.; Zini, I.; Rogawski, M.A.; Avoli, M. Endogenous neurosteroids modulate epileptogenesis in a model of temporal lobe epilepsy. Exp. Neurol. 2006, 201, 519-524. [CrossRef]

79. Burnham, W.M. The GABA hypothesis of kindling: Recent assay studies. Neurosci. Biobehav. Rev. 1989, 13, 281-288. [CrossRef]

80. Biagini, G.; Longo, D.; Baldelli, E.; Zoli, M.; Rogawski, M.A.; Bertazzoni, G.; Avoli, M. Neurosteroids and epileptogenesis in the pilocarpine model: Evidence for a relationship between P450scc induction and length of the latent period. Epilepsia 2009, 50, 53-58. [CrossRef]

81. Joshi, S.; Rajasekaran, K.; Williamson, J.; Kapur, J. Neurosteroid-sensitive $\delta$-GABA-A receptors: A role in epileptogenesis? Epilepsia 2017, 58, 494-504. [CrossRef]

82. Behr, C.; Lévesque, M.; Ragsdale, D.; Avoli, M. Lacosamide modulates interictal spiking and high-frequency oscillations in a model of mesial temporal lobe epilepsy. Epilepsy Res. 2015, 115, 8-16. [CrossRef] [PubMed]

83. Lévesque, M.; Behr, C.; Avoli, M. The anti-ictogenic effects of levetiracetam are mirrored by interictal spiking and high-frequency oscillation changes in a model of temporal lobe epilepsy. Seizure 2015, 25, 18-25. [CrossRef] [PubMed] 
84. Lucchi, C.; Costa, A.M.; Rustichelli, C.; Biagini, G. Allopregnanolone and pregnanolone are reduced in the hippocampus of epileptic rats, but only allopregnanolone correlates with the seizure frequency. Neuroendocrinology 2020. [CrossRef] [PubMed]

85. Pieribone, V.A.; Tsai, J.; Soufflet, C.; Rey, E.; Shaw, K.; Giller, E.; Dulac, O. Clinical evaluation of ganaxolone in pediatric and adolescent patients with refractory epilepsy. Epilepsia 2007, 48, 1870-1874. [CrossRef] [PubMed]

86. Sperling, M.R.; Klein, P.; Tsai, J. Randomized, double-blind, placebo-controlled phase 2 study of ganaxolone as add-on therapy in adults with uncontrolled partial-onset seizures. Epilepsia 2017, 58, 558-564. [CrossRef]

87. Trivisano, M.; Lucchi, C.; Rustichelli, C.; Terracciano, A.; Cusmai, R.; Ubertini, G.M.; Giannone, G.; Bertini, E.S.; Vigevano, F.; Gecz, J.; et al. Reduced steroidogenesis in patients with PCDH19-female limited epilepsy. Epilepsia 2017, 58, e91-e95. [CrossRef]

88. Samanta, D. PCDH19-Related Epilepsy Syndrome: A Comprehensive Clinical Review. Pediatr. Neurol. 2020, 105, 3-9. [CrossRef]

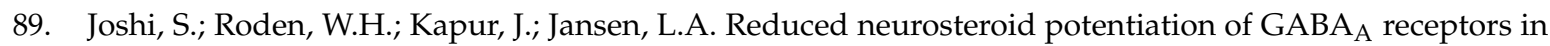
epilepsy and depolarized hippocampal neurons. Ann. Clin. Transl. Neurol. 2020, 7, 527-542. [CrossRef]

90. Rossetti, A.O. Place of neurosteroids in the treatment of status epilepticus. Epilepsia 2018, 59 (Suppl. S2), 216-219. [CrossRef]

91. Rosenthal, E.S.; Claassen, J.; Wainwright, M.S.; Husain, A.M.; Vaitkevicius, H.; Raines, S.; Hoffmann, E.; Colquhoun, H.; Doherty, J.J.; Kanes, S.J. Brexanolone as adjunctive therapy in super-refractory status epilepticus. Ann. Neurol. 2017, 82, 342-352. [CrossRef]

92. Meletti, S.; Lucchi, C.; Monti, G.; Giovannini, G.; Bedin, R.; Trenti, T.; Rustichelli, C.; Biagini, G. Low levels of progesterone and derivatives in cerebrospinal fluid of patients affected by status epilepticus. J. Neurochem. 2018, 147, 275-284. [CrossRef] [PubMed]

93. Meletti, S.; Lucchi, C.; Monti, G.; Giovannini, G.; Bedin, R.; Trenti, T.; Rustichelli, C.; Biagini, G. Decreased allopregnanolone levels in cerebrospinal fluid obtained during status epilepticus. Epilepsia 2017, 58, e16-e20. [CrossRef] [PubMed]

94. Espallergues, J.; Mamiya, T.; Vallée, M.; Koseki, T.; Nabeshima, T.; Temsamani, J.; Laruelle, C.; Maurice, T. The antidepressant-like effects of the $3 \beta$-hydroxysteroid dehydrogenase inhibitor trilostane in mice is related to changes in neuroactive steroid and monoamine levels. Neuropharmacology 2012, 62, 492-502. [CrossRef] [PubMed]

95. Young, J.; Corpéchot, C.; Perché, F.; Eychenne, B.; Haug, M.; Baulieu, E.E.; Robel, P. Neurosteroids in the mouse brain: Behavioral and pharmacological effects of a 3 beta-hydroxysteroid dehydrogenase inhibitor. Steroids 1996, 61, 144-149. [CrossRef]

96. Lucchi, C.; Costa, A.M.; Senn, L.; Messina, S.; Rustichelli, C.; Biagini, G. Augmentation of endogenous neurosteroid synthesis alters experimental status epilepticus dynamics. Epilepsia 2020. [CrossRef] [PubMed]

97. Herzog, A.G.; Fowler, K.M.; Smithson, S.D.; Kalayjian, L.A.; Heck, C.N.; Sperling, M.R.; Liporace, J.D.; Harden, C.L.; Dworetzky, B.A.; Pennell, P.B.; et al. Progesterone vs placebo therapy for women with epilepsy: A randomized clinical trial. Neurology 2012, 78, 1959-1966. [CrossRef] [PubMed]

98. Herzog, A.G.; Frye, C.A. Seizure exacerbation associated with inhibition of progesterone metabolism. Ann. Neurol. 2003, 53, 390-391. [CrossRef] [PubMed]

99. Pugnaghi, M.; Monti, G.; Biagini, G.; Meletti, S. Temporal lobe epilepsy exacerbation during pharmacological inhibition of endogenous neurosteroid synthesis. Case Rep. 2013, 2013, bcr2012008204. [CrossRef]

100. Avoli, M.; de Curtis, M.; Gnatkovsky, V.; Gotman, J.; Köhling, R.; Lévesque, M.; Manseau, F.; Shiri, Z.; Williams, S. Specific imbalance of excitatory/inhibitory signaling establishes seizure onset pattern in temporal lobe epilepsy. J. Neurophysiol. 2016, 115, 3229-3237. [CrossRef]

Publisher's Note: MDPI stays neutral with regard to jurisdictional claims in published maps and institutional affiliations. 